\title{
Post-depositional movement of methanesulphonic acid at Law Dome, Antarctica, and the influence of accumulation rate
}

\author{
Mark A.J. CURRAn,,${ }^{1}$ Anne S. PALMER, ${ }^{2}$ Tas D. VAn OMMEN, ${ }^{1}$ Vin I. MORGAN, \\ Katrina L. PHillips, ${ }^{2}$ Alison J. MaMORROW, ${ }^{2}$ Paul A. MAYEWSKi ${ }^{3}$ \\ ${ }^{1}$ Antarctic CRC and Australian Antarctic Division, Box 252-80, Hobart, Tasmania 7001, Australia \\ E-mail:mark.curran@utas.edu.au \\ ${ }^{2}$ IASOS, University of Tasmania, Box 252-77, Hobart, Tasmania 7001, Australia \\ ${ }^{3}$ Institute for Quaternary Research and Climate Studies, University of Maine, Orono, ME 04469-5790, U.S.A.
}

\begin{abstract}
A series of ice cores from sites with different snow-accumulation rates across Law Dome, East Antarctica, was investigated for methanesulphonic acid (MSA) movement. The precipitation at these sites (up to $35 \mathrm{~km}$ apart) is influenced by the same air masses, the principal difference being the accumulation rate. At the low-accumulation-rate W20k site (0.17 $\mathrm{m}$ ice equivalent), MSA was completely relocated from the summer to winter layer. Moderate movement was observed at the intermediate-accumulation-rate site $(0.7 \mathrm{~m}$ ice equivalent), Dome Summit South (DSS), while there was no evidence of movement at the high-accumulation-rate DE08 site (1.4 m ice equivalent). The main DSS record of MSA covered the epoch AD 1727-2000 and was used to investigate temporal post-depositional changes. Co-deposition of MSA and sea-salt ions was observed in the surface layers, outside of the main summer MSA peak, which complicates interpretation of these peaks as evidence of movement in deeper layers. A seasonal study of the 273 year DSS record revealed MSA migration predominantly from summer into autumn (in the up-core direction), but this migration was suppressed during the Tambora (1815) and unknown (1809) volcanic eruption period, and enhanced during an epoch (1770-1800) with high summer nitrate levels. A complex interaction between the gradients in nss-sulphate, nitrate and sea salts (which are influenced by accumulation rate) is believed to control the rate and extent of movement of MSA.
\end{abstract}

\section{INTRODUGTION}

Ice-core chemistry records contain climatic and environmental information over a wide range of time-scales. This information is retrieved by interpretation of validated and identified proxies. It is usually assumed that an ice-core chemistry signal is representative of the snow chemistry at the time of deposition, but changes during the deposition process, and post-depositional modification of the signal, are known to occur. It is therefore important to quantify the effects and understand the mechanisms involved, in order to assess the robustness of the proxy.

Post-deposition alterations of ice-core records can occur through diffusion, windpumping (including loss, addition and exchange), ablation, evaporation, melt, percolation and migration (Dibb, 1996; Waddington and others, 1996; Wolff, 1996). In terms of the major ions, surface losses of volatile species including nitrate (Mayewski and Legrand, 1990; Jones and others, 2001) and chloride (De Angelis and Legrand, 1995), additions of sulphate (Harder and others, 2000) and movement of nitrate (Kreutz and others, 1998) and magnesium (Wolff, 1996; Kreutz and others, 1998) have been documented at a number of ice-core sites throughout Antarctica.

Post-depositional movement of methanesulphonic acid (MSA) has attracted particular attention because of the importance of MSA in the climate system. MSA is an oxidation product of dimethylsulphide (DMS), which is produced by oceanic phytoplankton. DMS, through its oxidation products, is believed to affect the global climate system by influencing the production of cloud-condensation nuclei, which alter planetary cloud albedo, and subsequently affect biological productivity through feedback mechanisms (Charlson and others, 1987). The study of MSA and DMS in remote oceanic regions, such as the Southern Ocean, is particularly important in assessing the influence of natural sulphur processes on the climate system. In the Southern Ocean, peak production of DMS (Curran and Jones, 2000) and MSA (Ayers and others, 1991; Curran and others, 1998a; Minikin and others, 1998) occurs during the summer months, with the seasonal sea-ice zone identified as a large source region (Curran and others, 1998b). The MSA record in Antarctic ice cores is thus considered as a Southern Ocean proxy for biological activity, past DMS production, and also as an indicator of past sea-ice extent (Welch and others, 1993). Post-depositional changes of MSA in ice cores can place limits on environmental and climatic interpretation of such proxies.

Although MSA production is zero at high latitudes in winter (Ayers and others, 1991; Curran and others, 1998a; Minikin and others, 1998), records from some sites have shown winter peaks in subsurface layers. These peaks have been attributed to post-depositional movement (Wolff, 1996). This migration of MSA from summer to winter layers is observed in the Antarctic at Dolleman Island (Pasteur and Mulvaney, 2000), Siple Dome (Kreutz and others, 
Table 1. Information on the Law Dome cores and snow pit used in this study

Site Name Location Teardug/ Epoch used Accumulation

$m$ ice equiv.

\begin{tabular}{lccccc}
\hline DE08 & DEO8 & $66^{\circ} 43^{\prime} 19^{\prime \prime} \mathrm{S}, 113^{\circ} 11^{\prime} 58^{\prime \prime} \mathrm{E}$ & 1986 & $1841-79$ & 1.40 \\
DSS & snow pit $66^{\circ} 46^{\prime} 14^{\prime \prime} \mathrm{S}, 112^{\circ} 48^{\prime} 33^{\prime \prime} \mathrm{E}$ & 2000 & $1998-2000$ & 0.70 \\
DSS & S0.3k & $66^{\circ} 46^{\prime} 21^{\prime \prime} \mathrm{S}, 112^{\circ} 48^{\prime} 33^{\prime \prime} \mathrm{E}$ & 2000 & $1995-2000$ & 0.70 \\
DSS & DSS97 & $66^{\circ} 46^{\prime} 38^{\prime \prime} \mathrm{S}, 112^{\circ} 48^{\prime} 41^{\prime \prime} \mathrm{E}$ & 1997 & $1890-1995$ & 0.70 \\
DSS & DSS99 & $66^{\circ} 46^{\prime} 14^{\prime \prime} \mathrm{S}, 112^{\circ} 48^{\prime} 25^{\prime \prime} \mathrm{E}$ & 2000 & $1841-90$ & 0.70 \\
DSS & DSS & $66^{\circ} 46^{\prime} 11^{\prime \prime} \mathrm{S}, 112^{\circ} 48^{\prime} 25^{\prime \prime} \mathrm{E}$ & 1987 & $1727-1841$ & 0.70 \\
W20k & W20k & $66^{\circ} 46^{\prime} 27^{\prime \prime} \mathrm{S}, 112^{\circ} 21^{\prime} 26^{\prime \prime} \mathrm{E}$ & 1997 & $1806-17$ & 0.17
\end{tabular}

1998), Berkner Island (Wagenbach and others, 1994), Byrd (Langway and others, 1994) and the Filchner-Ronne Ice Shelf (Minikin and others, 1994). Doping of firn cores with MSA in laboratory tests has also demonstrated movement over an 8 month period (Pasteur and Mulvaney, 1999).

While the exact mechanism is not clearly understood, simple diffusion, percolation and other gravitational forces are not likely to produce migration since MSA appears to concentrate as new peaks in winter layers following relocation (Kreutz and others, 1998; Pasteur and Mulvaney, 2000). Recently, Pasteur and Mulvaney (2000) indicated that MSA movement depends on the concentration of other impurities and the annual accumulation rate at the site. A mechanism involving liquid- or vapour-phase diffusion and subsequent trapping by the formation of a cation salt in the winter layer has been suggested. Site temperature is also seen as a factor influencing migration (Pasteur and Mulvaney, 1999).

There is a steep gradient of snow accumulation from east to west across Law Dome due to the predominantly easterly airflow over the Dome. We use MSA records from three Law Dome ice-core sites, with well-resolved seasonality and different accumulation rates, to investigate movement of MSA out of the summer layer and the influence of snow-accumulation rate. Prior studies, based on limited data, suggested that MSA did not exhibit movement at Law Dome (Curran and others, 1998a). A new sub-seasonal-resolution MSA record from 1727 to 2000 has now been produced and is presented here with evidence of subtle post-depositional changes.

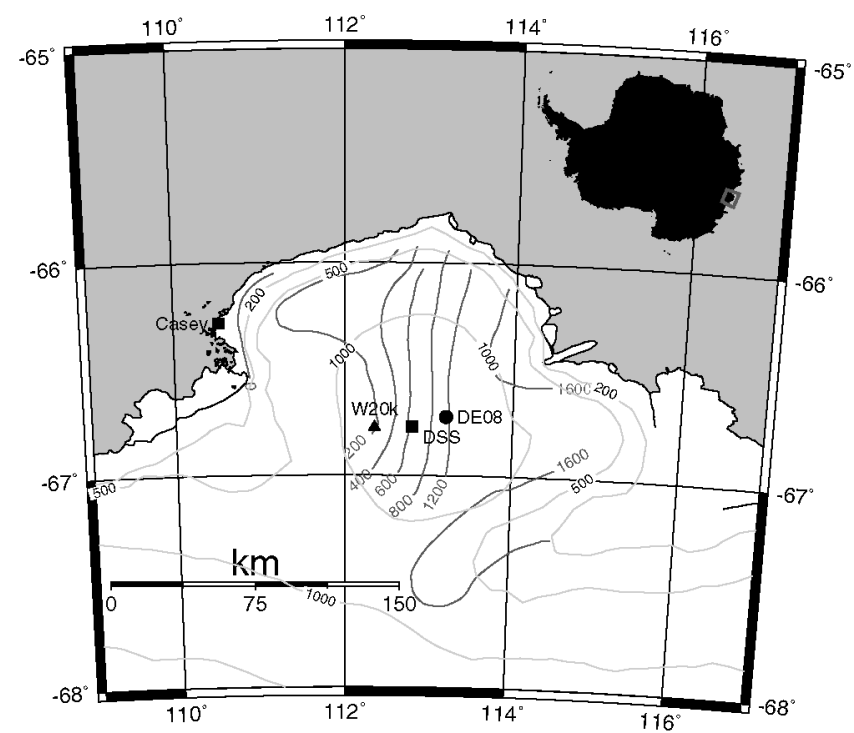

Fig. 1. Map of Law Dome with DE08, DSS and W20k sites.

\section{METHODS}

The ice cores used in this study were drilled at three main sites on Law Dome over the past 15 years (Table 1; Fig. 1). A snow pit was dug in February 2000 at the DSS site and sampled at $2.5 \mathrm{~cm}$ resolution (equivalent to approximately 50 samples per annual layer) according to methods detailed in McMorrow and others (2001). Ice-core samples from S0.3k, DSS99, DSS97 and DE08 were prepared and measured for trace ions at the Antarctic CRC, Hobart, using the methods described in Curran and Palmer (2001). The Dome Summit South (DSS) ice core (1727-1840) was analyzed for all major ions (except MSA) at the University of New Hampshire using techniques described in Buck and others (1992). Samples for MSA analysis were sent back to Hobart and analyzed according to Curran and Palmer (2001). Concentrations of nss-sulphate were calculated based on the seawater ratio of sodium to sulphate. The sea-water ratio used was corrected for sea-salt fractionation in a similar manner to Wagenbach and others (1998), although the correction was made for the entire annual cycle.

The records produced cover different epochs and different accumulation rates. A continuous high-resolution (12 uni-

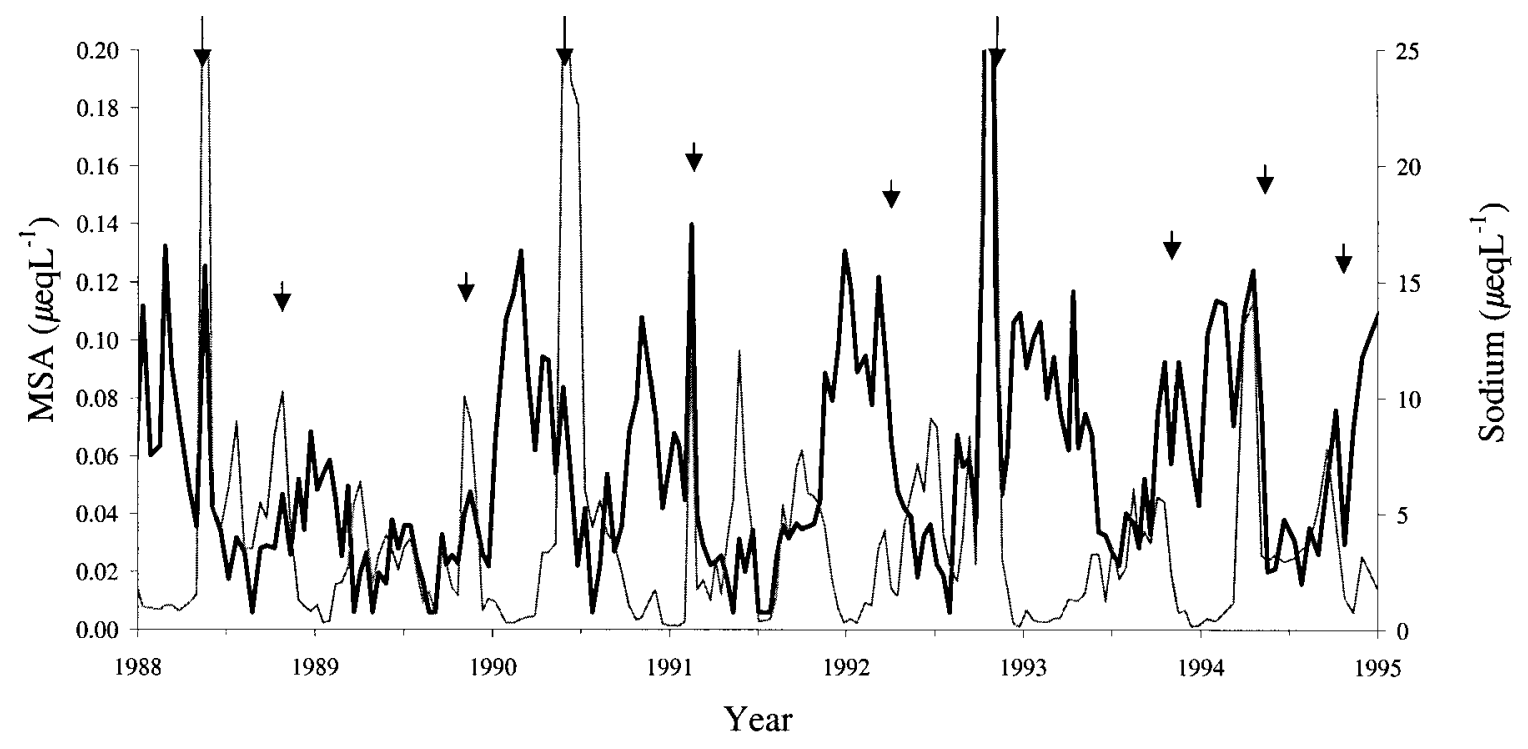

Fig. 2. Law Dome MSA and sodium records from DSS97 (1988-95). Arrows indicate concurrent MSA and sodium peaks. 


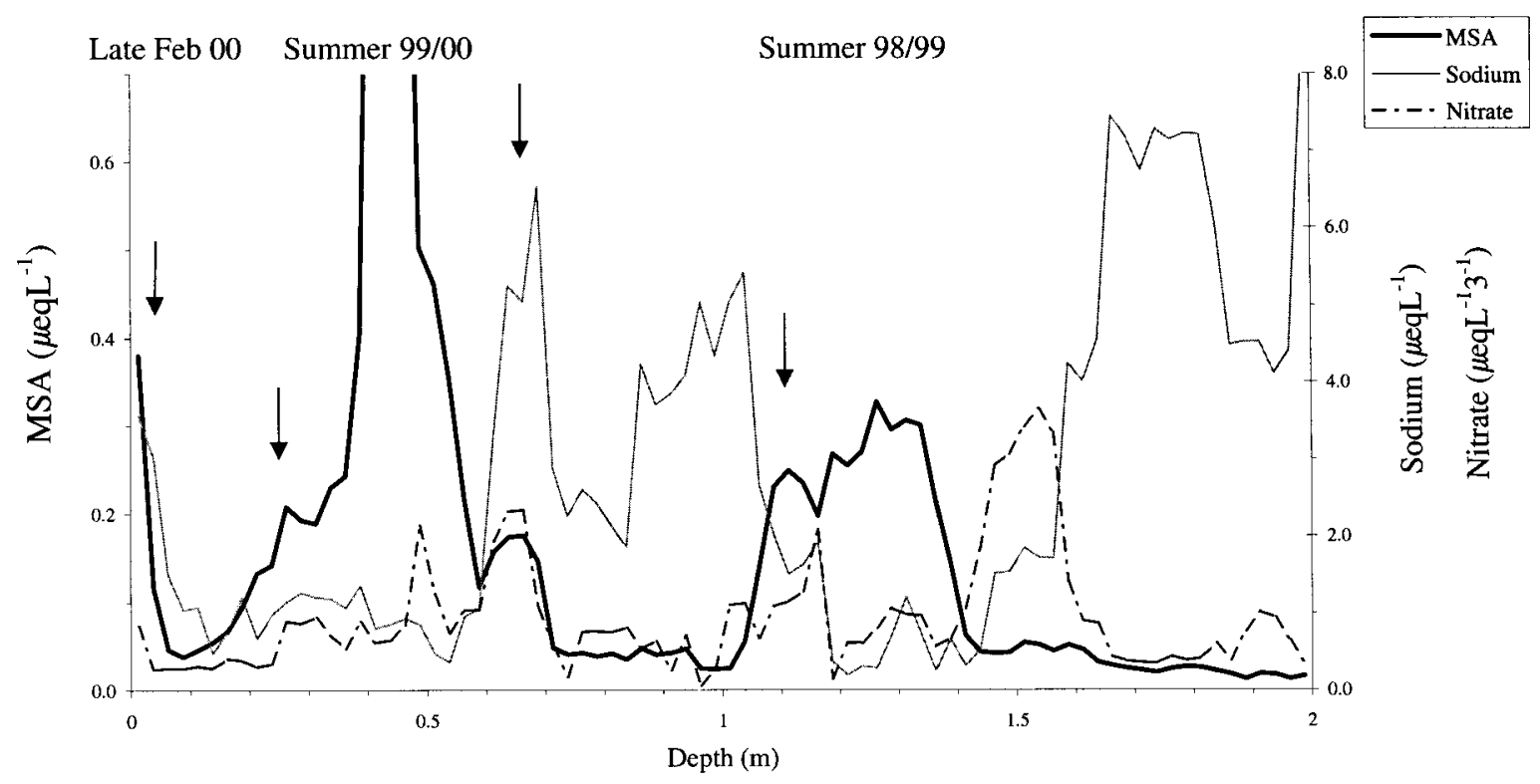

Fig. 3. MSA, sodium and nitrate snow-pit record at DSS (1998-2000). Arrowes indicate concurrent MSA and sodium peaks.

form time bins per year) record spanning the period 17272000 at the DSS site was obtained by combining data from four cores (S0.3k, DSS97, DSS99 and DSS; Table 1) according to the technique of Palmer and others (in press). The DE08 core was dated using the Tambora (Indonesia) volcanic horizon and uniquely matching the oxygen isotope seasonal profile to that from DSS. TheW20k core was dated by matching the volcanic doublet of Tambora and the unknown 1811 eruption to the DSS record. Annual accumulation rates for DSS and DE08 were taken from Morgan and others (1997). The mean accumulation rate for $\mathrm{W} 20 \mathrm{k}$, over the period 1916-97, was calculated from the depth at which the Tambora peak was located.

\section{RESULTS}

\section{Seasonal MSA deposition}

At Law Dome, the seasonal deposition of MSA and sea salts (e.g. sodium) is generally out of phase, with maximum MSA deposition and minimum sodium deposition in the austral summer. This can broadly be interpreted in terms of biological activity (which is highest in summer, producing high MSA levels) and storm activity (which is low in summer, resulting in low sodium levels). Despite this, throughout the 273 year record, there are regular concurrent peaks in both species (usually around early autumn and late spring). At depth, the peaks resemble wings on each side of the main summer peak, which may be interpreted as evidence of movement out of the summer layer into these sea-salt wings. However, these peaks occur in the top few seasons in ice cores (arrows in Fig. 2) and in fresh surface and near-surface snow-pit samples (arrows in Fig. 3). It is highly unlikely that rapid movement of MSA has occurred into these sea-salt peaks in the top couple of meters. The snow containing the surface peak in Figure $3(0-0.15 \mathrm{~m})$ was collected the day after snowfall in late February. Recently, high levels of MSA in atmospheric aerosols were observed in late summer-early autumn at Dumont d'Urville (Jourdain and Legrand, 2001). It is reasonable to consider that these marine species are co-deposited, outside of the main summer peak, but this raises questions about a secondary source of MSA.
Storm activity, which is responsible for elevated sodium levels, can lead to an increase in atmospheric MSA directly through increased DMS flux from surface waters associated with high wind speeds, or indirectly through transport of air from the sub-Antarctic region, which has a longer productivity season and is a known large source of DMS (Curran and Jones, 2000). Evidence from a study in progress to address the potential source pathways of these peaks through the combined investigation of snowfall events and regional meteorological conditions (McMorrow and others, 2002) suggests that the surface event identified in Figure 3 is a result of rapid advection of air masses from lower latitudes through cyclonic activity (consistent with a sub-Antarctic MSA source).

The surface peaks (Figs 2 and 3) are quite small relative to the main summer MSA peak. However, deeper in the DSS record these peaks are larger (relative to the summer peak) and suggest either that these MSA-sodium storms were stronger in the past (and the changes reflect real deposition changes) or that summer MSA has migrated into these peaks.

\section{Influence of snow-accumulation rate}

The MSA record from the higher-accumulation-rate DE08 site (to the east of DSS; Fig. 1), which spans the period 184179, was investigated for these MSA-sodium peaks. The records of other major ions and oxygen isotopes at DE08 overlay with those from DSS for the same epoch, and similar recent changes in accumulation rate and oxygen isotope ratios have been seen at these sites (Morgan and others, 1991), indicating the sites are influenced by the same snowfall events. Complex sub-seasonal features show excellent agreement and were used to corroborate dating between the cores (Palmer and others, in press). MSA-sodium peaks were present in the DE08 record, but were relatively small and very infrequent.

The mean seasonal cycles (1841-79) of nss-sulphate and MSA calculated for DSS and DE08 according to Curran and others (1998a) are shown in Figure 4. The austral calendar seasons are loosely defined as summer 0.9-0.2, autumn $0.2-0.4$, winter $0.4-0.7$, spring $0.7-0.9$. The seasonality of nsssulphate agrees well for these cores, illustrating the strong summer maximum and winter minimum. The seasonality of MSA was quite different. The seasonal cycle at the higher- 

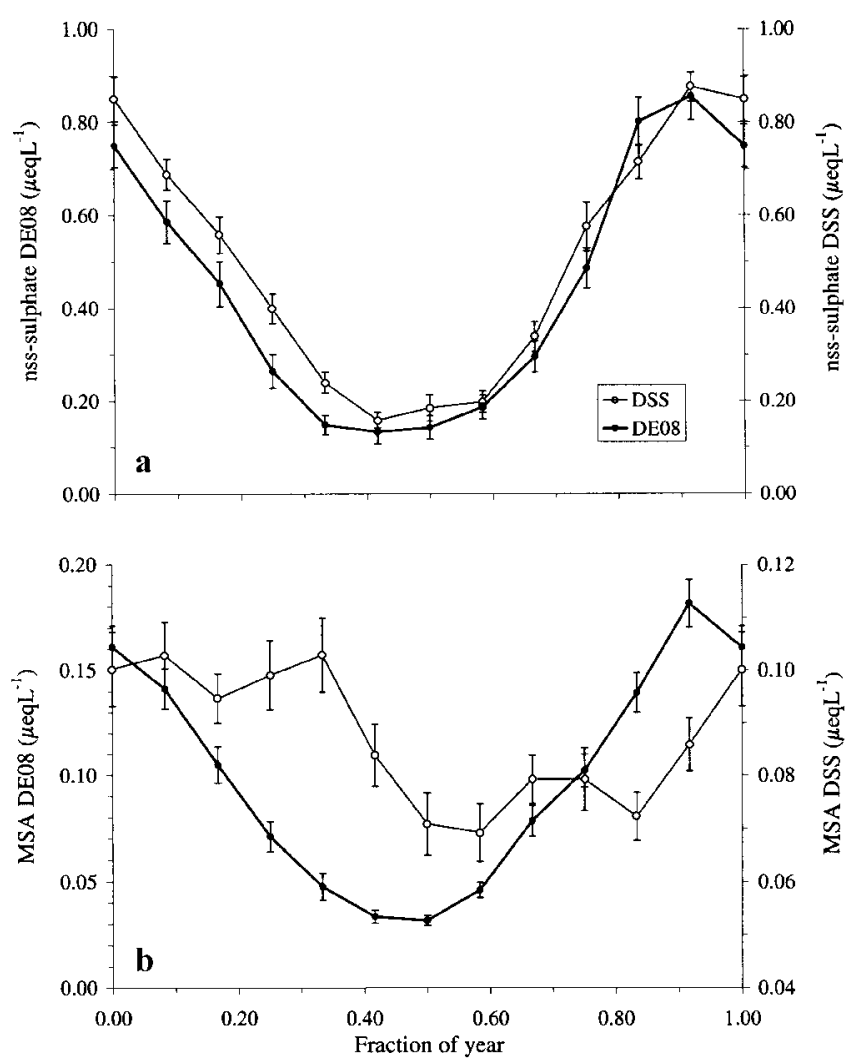

Fig. 4. Mean seasonal cycles of MSA and nss-sulphate at DE08 and DSS (1840-79).

accumulation-rate DE08 site was consistent with surface cycles at DSS, with a clear summer maximum and winter minimum. These cycles are very clearly seen in the time-series data (not shown), and the infrequency of deviations from this cycle was small (as seen by the small error bars in Fig. 4). The mean seasonal cycle for the same period at DSS shows a broad summer-autumn peak, elevated winter and slightly elevated spring peak (Fig. 4). This implies that MSA has moved at DSS, since the seasonal pattern for the 1841-79 epoch does not agree with surface deposition patterns, or with the seasonality for the same period at DE08. Although this indicates MSA has migrated out of the summer deposition layer, a winter peak was not formed, as is seen at other sites (e.g. Kreutz and others, 1998; Pasteur and Mulvaney, 2000). However, at the lower-accumulation-rate W20k site further to the west of DSS (Fig. 1), MSA shows relocation completely into the winter layers (Fig. 5). MSA forms clear peaks in the winter layer and is out of phase with nss-sulphate.

The absolute concentration of MSA in the ice is not a critical factor for movement. Pasteur and Mulvaney (2000) observed MSA movement at sites with mean concentrations of $0.8-0.08 \mu \mathrm{eq} \mathrm{L}^{-1}$. We see full relocation to the winter layer at W20k where the mean MSA concentration is $0.03 \mu \mathrm{eq} \mathrm{L}^{-1}$, and no evidence of movement at DE08 with a mean concentration of $0.10 \mu \mathrm{eq} \mathrm{L}^{-1}$.

\section{Temporal changes in the MSA seasonal signal at the DSS site}

The full MSA record at DSS spanning the period 17272000 has been dated using multi-species annual-layer counting and has a possible error of \pm 1 year between 1806 and 1727 (Palmer and others, in press). The major-ion data were resampled on a uniform time grid, at 12 bins per year (nominal "monthly" sampling), using linear interpolation. The data were then arranged in a two-dimensional matrix by year and "month" and then smoothed by monthly bin with a Gaussian filter having 10 year equivalent width (2.5 year sigma) in the manner of Morgan and Van Ommen (1997). In the case of MSA, there was significant decadal and longer-scale variability, and the 12-bin data were expressed as a ratio to the maximum for each year. This gives a measure of where the MSA is concentrated within each annual cycle when plotted against fraction of calendar year (Fig. 6a). Austral summer is centered around zero, and winter around 0.5 fraction of a year $(\mathrm{yr})$.

At the top of the record (1980-2000, MSA is deposited mostly at 0.9-0.2 yr (approximately late December-January), with very little deposited at $0.3-0.7 \mathrm{yr}$ (Fig. 6a). There is a distinct "V" shape to the MSA ratio record between the surface and 1950 (approximately $40 \mathrm{~m}$ ). This implies a gradual increase in the seasonal length of the MSA signal. A broad summer-autumn maximum is established, with slightly elevated winters. In addition, there is an asymmetry to the modified MSA signal, with spreading predominantly into autumn (in the up-core direction). There is minimal move-

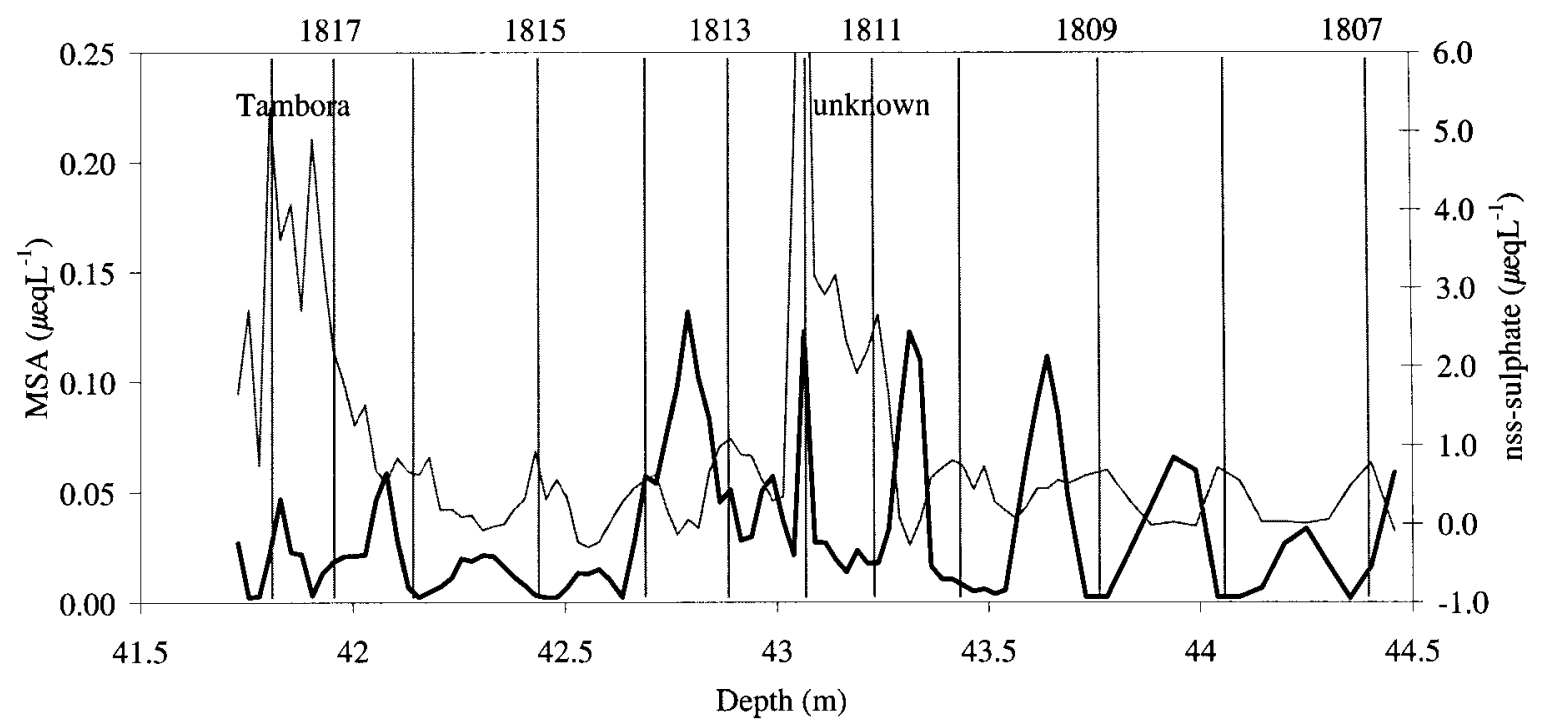

Fig. 5. MSA and nss-sulphate records from W20k (1807-18). The vertical lines represent the approximate mid-summer boundaries (given by the nss-sulphate trace). 


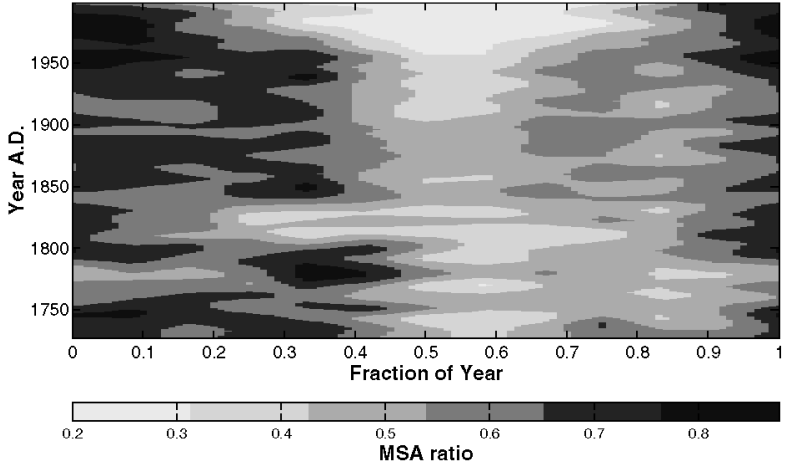

(a)

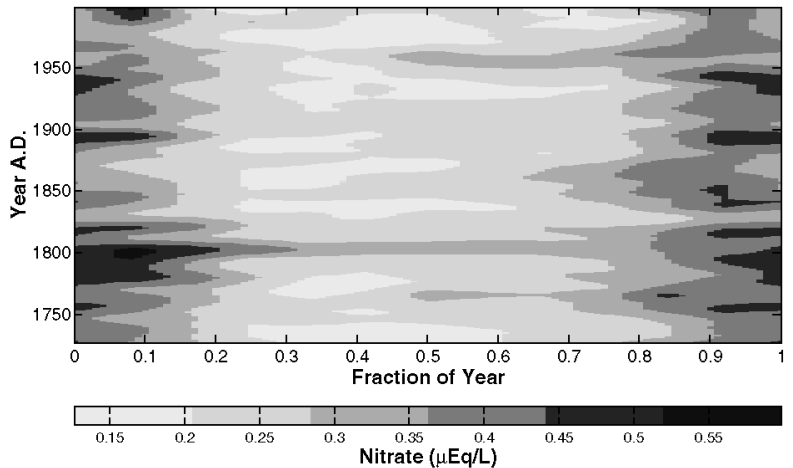

(c)

Fig. 6. Seasonal variability, 1727-2000, at DSS for (a) MSA seasonal ratio, (b) nss-sulphate, (c) nitrate and (d) MSA seasonal residual ratio (only years 1727-95).

ment into spring, with only a few high ratios found at $0.7-$ $0.8 \mathrm{yr}$. The extent of movement appears to generally stabilize around 1950, and further creeping of MSA into the winter layer does not appear to occur.

There are two features that stand apart from this trend, namely, the apparent lack of spreading in the region dated 1800-40 (approximately 120-145 m), and the loss of summer signal or enhanced spreading between about 1770 and 1800 (approximately 150-160 m). These two features are synchronous with anomalies in the nss-sulphate (Fig. 6b) and nitrate (Fig. 6c) records, respectively. The period 1800-40 contains two large volcanic eruption signatures, namely, Tambora (1815) and an unknown eruption with an ice date of 1811 (Palmer and others, in press). These volcanic signatures elevate both summer and winter levels in the nss-sulphate trace (Fig. 6b). MSA does not appear to move in the period containing this nss-sulphate anomaly. This indicates that the increased acidity, and seasonal extent of this high acidity, may restrict MSA from migrating out of the summer layer.

The opposite appears to be the case for the effect of the nitrate anomaly (Fig. 6c). High summer nitrate and an increase in the seasonal extent of the summer peak is seen between around 1770 and 1800. This corresponds to the MSA showing enhanced migration and decrease in the summer MSA signal. It appears that these high-nitrate conditions force MSA further out from the summer layer.

These anomalies may be seen in the MSA ratio residual trace, which covers the period 1727-1995 (Fig. 6d). This figure was generated by subtracting the mean seasonal cycle of the MSA ratio, for the period 1980-95, from each annual cycle. This leaves a residual signal highlighting MSA movement. The signal above about 1970 is completely lost (i.e. there is no significant relocation relative to the 1980-95 epoch). The strong autumn signals are evident, but winter and spring signals appear in the residual plot since the per-

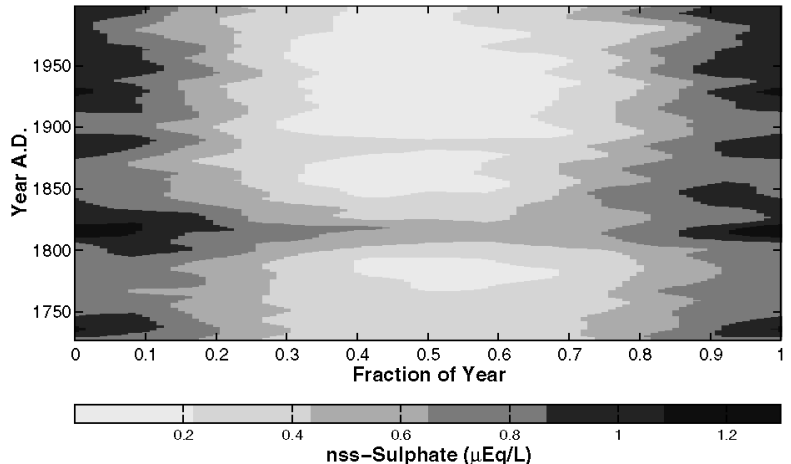

(b)

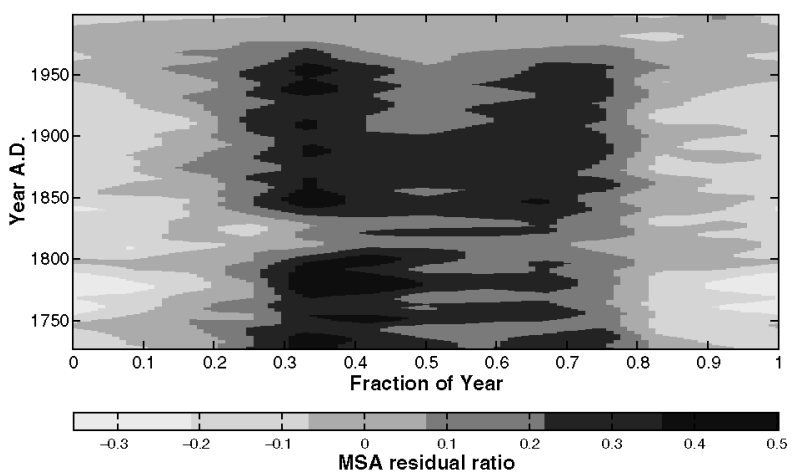

(d)

centage MSA change is large, although the absolute change is small. The enhancement of MSA at $0.3-0.4 \mathrm{yr}$ is clearly seen, with the reduced movement during the volcanic years (1800-40) and further enhanced movement (and summer decrease) during the nitrate anomaly (1770-1800).

\section{DISGUSSION}

Co-deposition of MSA and sodium at Law Dome is observed out of the central summer period, probably as a result of cyclonic activity advecting relatively MSA-rich air from lower latitudes. This near-surface signal can be confused with MSA migration, making it difficult to distinguish between co-deposition and movement. It is possible that the spring or autumn MSA-sea-salt wings become sites where MSA concentrates following movement out of the summer snow. At increasing depth, these wings increase in size relative to the summer MSA peak, forming secondary maxima in MSA. These peaks are seen in the mean seasonal cycle at DSS for the period 1841-79 (Fig. 4) and throughout the 283 year record at $0.3-0.4 \mathrm{yr}$ and to a much lesser extent at $0.7-0.8 \mathrm{yr}$ (Fig. 6a). Pasteur and Mulvaney (2000) observed a general trend toward an increasing number of winter peaks with depth at Dolleman Island, whereas we observe a gradual spreading of the summer peak into the autumn layer. This is a real post-depositional seasonal change, since it is not seen for the same epoch at the higher-accumulation-rate DE08 site (Fig. 4), and it is seen to a greater extent at the low-accumulation-rateW20k site (Fig. 5). Law Dome offers an ideal environment for the study of MSA movement, with sites closely spaced, exposed to the same air masses, showing varying degrees of post-depositional change. The conditions are suitable for limited movement at DSS, whereas conditions at 
W20k are more conducive to movement, while the highaccumulation-rate DE08 site shows little or no movement.

Accumulation rate alone may affect the extent of movement by simply providing a greater distance for MSA to move. Alternatively, the acidic gradient (which is directly affected by accumulation rate) may control the degree of movement. The concentration of acidic species is not that different between the sites (mean concentrations of 0.33$0.37 \mu \mathrm{eq} \mathrm{L} \mathrm{L}^{-1}$ ), so the extent of movement is not likely to be related to the absolute concentration. Movement at a particular site, however, may be more related to the summerwinter gradient of acidity, which is stronger at lower-accumulation-rate sites. At DSS in the epoch 1800-40, acidity levels are high throughout the year due to volcanic sulphate, reducing the summer-winter acidity gradient (Fig. 6b). This reduction in the acid gradient appears to confine the summer MSA peak within the broad seasonal acidic peak (during the deposition process), and movement appears to be restricted (Fig. 6a).

Nitrate levels also appear to affect movement, and maybe to a greater extent than a similar concentration of nss-sulphate. Between approximately 1770 and 1800, MSA completely moves out of the summer (Fig. 6a), where summer nss-sulphate levels are relatively low (Fig. 6b) but nitrate is high (Fig. 6c). This results in a higher than average concentration of MSA at $0.3-0.4 \mathrm{yr}$ and depletion in summer at $0-0.1$ yr during this period (Fig. 6d). This enhanced effect may be due to differences in the location or form of nitrate relative to nss-sulphate within the snowpack.

The asymmetric movement of MSA, particularly since it is in the up-core direction, rules out gravitational movement and simple diffusion, and is consistent with theories proposed by Kreutz and others (1998) and Pasteur and Mulvaney (2000). At DSS there is only slight movement of MSA in the down-core direction (Fig. 6a). This is despite the fact that seasalt peaks are situated closer to MSA peaks at the down-core end. The sea-salt signal (not shown) peaks between around $0.4 \mathrm{yr}$ (late autumn-early winter) and $0.8 \mathrm{yr}$ (i.e. in later winter-early spring) at DSS. The spring sea-salt peak is only $\sim 0.1$ yr away from the beginning of the summer MSA peak, whereas the autumn sea-salt peak is $\sim 0.2 \mathrm{yr}$ away from the trailing edge of the MSA peak (in the up-core direction). Therefore MSA must travel further to reach the autumn seasalt peak, indicating an interaction restricting analogous movement in the down-core direction. The acidic species, particularly nitrate, peak in late spring-early summer, prior to the MSA maximum (see nitrate early-summer peaks from snow-pit record in Figure 2, and aerosol data from Wagenbach and others (1998)). In light of the trends observed during the volcanic fallout period, we are led to consider a late-springearly-summer "acid barrier" which precludes movement of MSA in this direction. MSA, which peaks later than the acidic species, can then only move along the acid gradient into autumn, in the up-core direction.

MSA is believed to move into the sea-salt layer, forming a stable cation salt, through a metathesis reaction, which removes it from solution, creating a gradient and causing more MSA to move (Kreutz and others 1998; Pasteur and Mulvaney, 2000). This is consistent with our results, which show that MSA appears to concentrate at the sea-salt boundary at DSS. There is likely to be a limit to the migration distance along which MSA can penetrate into the seasalt layer, which will depend on the sea-salt concentration gradient. Although some MSA moves fully into the winter in some years, on average MSA does not peak in the winter layer. The majority of MSA appears to move into autumn at DSS, on the edge of the sea-salt layer, and move no further. The concentration of sea salts at DE08 (e.g. sodium = $\left.4.2 \mu \mathrm{eq} \mathrm{L}{ }^{-1}\right)$ is not that different and if anything slightly higher than at DSS (e.g. sodium $=3.8 \mu \mathrm{eq} \mathrm{L} \mathrm{L}^{-1}$ ) for the epoch 1841-79. The accumulation rate is, however, double that of DSS, which significantly increases the distance for movement, and decreases the sea-salt and acidity gradients. Alternatively, MSA may not have the time to move into the winter layer at DSS due to the combination of layer thickness and porosity which is continually decreasing during firnification. The gradual spreading seen as the "V" shape in Figure $6 \mathrm{a}$ indicates that depth (or age) after deposition is a factor affecting the extent of migration. This movement is restricted to within the firn layer, and does not appear to continue in the deeper ice layers. It is difficult to conclude at this stage which factors are limiting further movement at DSS below 1950, but it is assumed to be related to pore close-off.

\section{CONCLUDING REMARKS}

Post-depositional movement of MSA from summer into autumn layers (up-core direction) was observed in the 273 year DSS Law Dome ice-core record. However, suppression of movement was observed during the volcanic period containing the Tambora and 1811 eruption signatures, and enhanced movement was associated with a high summer nitrate anomaly. The extent of movement was markedly different between sites with different accumulation rates. Movement was not evident at DE08 (1.4 m ice equivalent), limited at DSS $(0.70 \mathrm{~m}$ ice equivalent $)$ and extensive at W20k $(0.17 \mathrm{~m}$ ice equivalent). Our results suggest that MSA migration is controlled by the gradients of major-ion constituents (nss-sulphate, nitrate and sea salts), which are directly related to accumulation rate.

The migration of MSA has implications for interpreting the seasonal changes in the MSA record and the MSA/nsssulphate ratio. This ratio has been used in studies to indicate changes in MSA source strength, related to biological activity changes. Movement of MSA from summer (where it has comparable levels to nss-sulphate) to autumn or winter (where MSA will dominate) will affect the seasonality of this ratio. Mean annual ratios should not be affected provided they are calculated from the ratio of the mean annual concentrations and not from the mean of the individual ratios. Multi-year averages in both the MSA record and the MSA/nss-sulphate ratio will not be affected by movement since it is confined within an annual layer.

\section{REFERENGES}

Ayers, G. P., J. P. Ivey and R.W. Gillet. 1991. Coherence between seasonal cycles of dimethyl sulphide, methanesulphonate and sulphate in marine air. Nature, 349(6308), 404-406.

Buck, C. F., P. A. Mayewski, M. J. Spencer, S. Whitlow, M. S. Twickler and D. Barrett. 1992. Determination of major ions in snow and ice cores by ion chromatography. Chromatogr., Ser. A, 594, 225-228.

Charlson, R. J., J. E. Lovelock, M. O. Andreae and S. G. Warren. 1987. Oceanic phytoplankton, atmospheric sulphur, cloud albedo and climate. Nature, 326(6114), 655-661.

Curran, M. A. J. and G. B. Jones. 2000. Dimethyl sulfide in the Southern Ocean: seasonality and flux. 7. Geophys. Res., 105(D16), 20,451-20,459.

Curran, M. A. J. and A. S. Palmer. 2001. Suppressed ion chromatography methods for the routine determination of ultra low level anions and cations in ice cores. F. Chromatogr., Ser. A, 919(1), 107-113. 
Curran, M. A. J., T. D. van Ommen and V. Morgan. 1998a. Seasonal characteristics of the major ions in the high-accumulation Dome Summit South ice core, Law Dome, Antarctica. Ann. Glaciol., 27, 385-390.

Curran, M. A. J., G. B. Jones and H. Burton. 1998b. The spatial distribution of DMS and DMSP in the Australasian sector of the Southern Ocean. $\mathcal{F}$. Geophys. Res., 103(D13), 16,677-16,689.

De Angelis, M. and M. Legrand. 1995. Preliminary investigations of post depositional effects of $\mathrm{HCl}, \mathrm{HNO}_{3}$, and organic acids in polar firn layers. In Delmas, R. J., ed. Ice core studies of global biogeochemical cycles. Berlin, etc., Springer-Verlag, 361-381. (NATO ASI Series I: Global Environmental Change 30.)

Dibb, J. E. 1996. Overview of field data on the deposition of aerosol-associated species to the surface snow of polar glaciers, particularly recent work in Greenland. InWolff, E.W. and R. C. Bales, eds. Chemical exchangebetween the atmosphere and polar snow. Berlin, etc., Springer-Verlag, 249-274. (NATO ASI Series I: Global Environmental Change 43.)

Harder, S., S. G. Warren and R. J. Charlson. 2000. Sulphate in air and snow at the South Pole: implications for transport and deposition at sites with low snow accumulation. 7. Geophys. Res., 105(D18), 22,825-22832.

Jones, A. E. and 6 others. 2001. Measurements of $\mathrm{NO}_{x}$ emissions from the Antarctic snowpack. Geophys. Res. Lett., 28(8), 1499-1502.

Jourdain, B. and M. Legrand. 2001. Seasonal variations of atmospheric dimethylsulfide, dimethylsulfoxide, sulfur dioxide, methanesulfonate, and non-sea-salt sulfate aerosols at Dumont d'Urville (coastal Antarctica) (December 1998 to July 1999). F. Geophys. Res., 106(D13), 14,391-14,408.

Kreutz, K. J., P. A. Mayewski, S. I. Whitlow and M. S. Twickler. 1998. Limited migration of soluble ionic species in a Siple Dome, Antarctica, ice core. Ann. Glaciol., 27, 371-377.

Langway, C. C., Jr, K. Osada, H. B. Clausen, C. U. Hammer, H. Shoji and A. Mitani. 1994. New chemical stratigraphy over the last millennium for Byrd Station, Antarctica. Tellus, 46B(1), 40-51.

Mayewski, P. A. and M. Legrand. 1990. Recent increase in nitrate concentration of Antarctic snow. Nature, 346(6281), 258-260.

McMorrow, A. J., M. A. J. Curran, T. D. van Ommen, V. I. Morgan, M. A. J. Pook and I. Allison. 2001. Intercomparison of firn core and meteorological data. Antarct. Sci., 13(3), 329-337.

McMorrow, A. J., M. A. J. Curran, T. D. van Ommen, V. Morgan and I. Allison. 2002. Features of meteorological events preserved in a highresolution Law Dome (Antarctica) snow pit. Ann. Glaciol., 35 (see paper in this volume).

Minikin, A., D. Wagenbach, W. Graf and J. Kipfstuhl. 1994. Spatial and seasonal variations of the snow chemistry at the central Filchner-Ronne Ice Shelf, Antarctica. Ann. Glaciol., 20, 283-290.

Minikin, A. and 7 others. 1998. Sulfur-containing species (sulfate and methanesulfonate) in coastal Antarctic aerosol and precipitation. 7. Geophys. Res., 103(D9), 10,975-10,990.

Morgan, V. and T. D. van Ommen. 1997. Seasonality in late-Holocene climate from ice-core records. Holocene, 7 (3), 351-354.

Morgan, V. I., I. D. Goodwin, D. M. Etheridge and C.W. Wookey. 1991. Evidence from Antarctic ice cores for recent increases in snow accumulation. Nature, 354(6348), 58-60.

Morgan, V. I., C.W. Wookey, Li Jun, T. D. van Ommen, W. Skinner and M. F. Fitzpatrick. 1997. Site information and initial results from deep ice drilling on Law Dome, Antarctica. 7. Glaciol., 43(143), 3-10.

Palmer, A. S., T. D. van Ommen, M. A. J. Curran, V. Morgan, J. M. Souney and P. A. Mayewski. In press. Dating of major volcanic eruptions from a seven century Law Dome ice core record. F. Geophys. Res.

Pasteur, E. C. and R. Mulvaney. 1999. Laboratory study of the migration of methane sulphonate in firn. F. Glaciol., 45(150), 214-218.

Pasteur, E. and R. Mulvaney. 2000. Migration of methane sulphonate in Antarctic firn and ice. 7. Geophys. Res., 105(D9), 11,525-11,534.

Waddington, E. D., J. Cunningham and S. L. Harder. 1996. The effects of snow ventilation on chemical concentrations. In Wolff, E. W. and R. C. Bales, eds. Chemical exchange between the atmosphere and polar snow. Berlin, etc., Springer-Verlag, 403-451. (NATO ASI Series I: Global Environmental Change 43.)

Wagenbach, D. and 6 others. 1994. Reconnaissance of chemical and isotopic firn properties on top of Berkner Island, Antarctica. Ann. Glaciol., 20, 307-312.

Wagenbach, D. and 7 others. 1998. Sea-salt aerosol in coastal Antarctic regions. 7. Geophys. Res., 103(D9), 10,961-10,974.

Welch, K. A., P. A. Mayewski and S. I. Whitlow. 1993. Methanesulfonic acid in coastal Antarctic snow related to sea ice extent. Geophys. Res. Lett., 20(6), 443-446.

Wolff, E.W. 1996. Location, movement and reactions of impurities in solid ice. In Wolff, E. W. and R. C. Bales, eds. Chemical exchange between the atmosphere and polar snow. Berlin, etc., Springer-Verlag, 541-560. (NATO ASI Series I: Global Environmental Change 43.) 